\title{
Excision of breast fibroepithelial lesions - when is it still necessary?: a 10-year review of a regional centre
}

\section{Dorsa Mousadoust}

The University of British Columbia Faculty of Medicine

\section{Carol Dingee}

Providence Health Care

\section{Leo Chen}

The University of British Columbia Faculty of Medicine

Amy Bazzarelli

The University of British Columbia Faculty of Medicine

\section{Urve Kuusk}

Providence Health Care

\section{Jin-Si Pao}

Providence Health Care

\section{Rebecca Warburton}

Providence Health Care

Elaine McKevitt ( $\nabla$ emckevitt@providencehealth.bc.ca )

Providence Health Care https://orcid.org/0000-0002-9080-113X

\section{Research Article}

Keywords: Fibroadenoma, Phyllodes tumor, High risk breast lesion, Core needle biopsy, Surgical excision

Posted Date: October 21st, 2021

DOl: https://doi.org/10.21203/rs.3.rs-916352/v1

License: (c) (1) This work is licensed under a Creative Commons Attribution 4.0 International License. Read Full License 


\section{Excision of breast fibroepithelial lesions - when is it still necessary?:}

\section{a 10-year review of a regional centre}

Dorsa Mousadoust ${ }^{\mathrm{b}}$, Carol K. Dingee MD ${ }^{\mathrm{a}, \mathrm{b}}$, Leo Chen MSc ${ }^{\mathrm{b}}$, Amy Bazzarelli MD ${ }^{\mathrm{a}, \mathrm{b}}$, Urve Kuusk MD ${ }^{\mathrm{a}, \mathrm{b}}$, Jin-Si Pao MD ${ }^{\mathrm{a}, \mathrm{b}}$, Rebecca Warburton MD ${ }^{\mathrm{a}, \mathrm{b}}$, Elaine C. McKevitt MEd MD

${ }^{a}$ Providence Breast Centre, Mount Saint Joseph Hospital, 3080 Prince Edward St, Vancouver, BC V5T 3N4, Canada

${ }^{b}$ Faculty of Medicine, University of British Columbia, 317-2194 Health Sciences Mall, Vancouver, BC V6T 1Z3, Canada

\section{CORRESPONDING AUTHOR:}

Elaine McKevitt, MD, FRCSC, FACS

emckevitt@ providencehealth.bc.ca

(T): 604-877-8511 (F): 604-877-8506

Providence Breast Centre

Mount Saint Joseph Hospital

3080 Prince Edward Street

Vancouver, BC V5T 3N4, Canada 


\section{ABSTRACT}

\section{Purpose}

Fibroepithelial lesions (FEL) range from benign fibroadenoma (FA) to malignant phyllodes tumor (PT), but can be difficult to diagnose on core needle biopsy (CNB). This study assesses risk factors for phyllodes tumor (PT) and recurrence and whether the policy to excise FELs over $3 \mathrm{~cm}$ in size is justified.

\section{Methods}

Patients having surgery for FELs from 2009-2018 were identified. The association of clinical, radiology and pathological features with PT and recurrence were evaluated. Trend analysis was used to assess risk of PT based on imaging size.

\section{Results}

Of the 616 patients with FELs, 400 were identified as having FA on CNB and 216 were identified as having FEL with a comment of concern for phyllodes tumor (QPT). PT was identified in 107 cases, 28 had CNB of FA (7.0\%) while 79 had QPT (36.6\%). Follow-up was available for 86 with a mean of 56 months; 6 patients had recurrence of PT, all of whom had QPT on CNB. The finding of PT was associated with CNB of QPT, increasing age and size on multivariate logistic regression. All patients diagnosed with PT following CNB of FA had enlarging lesions with a mean size of $38.3 \mathrm{~mm}$.

\section{Conclusions}

Our data does not support routine excision of FELs at $3 \mathrm{~cm}$. Patients with QPT on CNB should consider excision due to high risk of PT and recurrence and the decision to excise FAs to rule out PT should also consider whether the lesion is enlarging.

\section{Keywords:}

Fibroadenoma

Phyllodes tumor

High risk breast lesion

Core needle biopsy

Surgical excision 


\section{DECLARATIONS:}

Funding: There was no funding for this study.

Conflicts of interest/Competing interests: The authors declare that they have no conflict of interest.

Availability of data and material: All data generated or analysed during this study are reported in this published article

Code availability: N/A

Authors' contributions: All authors contributed to the study conception and design. Material preparation and data collection were performed by Dorsa Mousadoust, Dr. Carol Dingee, Dr. Amy Bazzarelli, Dr. Urve Kuusk, Dr. Jin-Si Pao, Dr. Rebecca Warburton, and Dr. Elaine McKevitt. Analysis was performed by Dorsa Mousadoust, Dr. Elaine McKevitt, and Leo Chen. The first draft of the manuscript was written by Dorsa Mousadoust and Dr. Elaine McKevitt and all authors commented on previous versions of the manuscript. All authors read and approved the final manuscript.

Ethics approval: This retrospective study involving human participants was in accordance with the ethical standards of the institutional and national research committee and with the 1964 Helsinki Declaration and its later amendments or comparable ethical standards. The research ethics board of the University of British Columbia and Providence Health care approved this study.

Consent to participate: N/A

Consent for publication: N/A 


\section{INTRODUCTION:}

Fibroepithelial lesions (FEL) are a heterogenous group of neoplasms that range from benign fibroadenoma (FA) to malignant phyllodes tumor (PT). While FAs do not require routine excision and many can be safely managed with observation, PTs require excision due to concerns about potential for malignant transformation and recurrence. Prior to the use of Core Needle Biopsy (CNB), larger lesions were excised to avoid missing PT but it is unknown whether this remains necessary for all FELs.

It can be difficult to distinguish FA from PT on CNB due to overlapping histological features even when multiple stringent histological criteria are applied [1]. In such instances pathologists may designate the lesion as FEL and then add a comment of concern such as "cannot rule out phyllodes." When there is histological ambiguity, the WHO recommends favouring a diagnosis of FA over PT for these query phyllodes tumors (QPT) in order to avoid overtreatment [2]. However, there is a concern that a PT may be missed so many patients and surgeons favor excision. The National Comprehensive Cancer Network (NCCN) guidelines recommend excision of FEL over $3 \mathrm{~cm}$ in size to avoid missing PT [3]. However, we have been unable to find literature to support this size threshold. At out institution we recommend excision of lesions with CNB of QPT and we have individualized decisions for surgery when the CNB showed FA, taking into account size, radiology-pathology concordance, symptoms, enlargement, and patient preference.

The first objective of this study is to assess whether the convention to excise FELs $3 \mathrm{~cm}$ in size or greater is necessary. The second objective is to look for risk factors for upstaging to PT and identify a low-risk group that can be spared surgery.

\section{METHODS:}

Ethical approval:

This study was approved by the University of British Columbia Research Ethics Board.

Patients having surgical excision of FELs on CNB at Mount Saint Joseph Hospital from 2009-2018 were identified from a prospective database and chart review was used to supplement clinical data and obtain follow-up. Patients 
were included if they had a FEL on CNB and excluded if the CNB was diagnostic of PT or if the CNB also had other pathology concerning for malignancy, such as Ductal Carcinoma in Situ or Atypical Ductal Hyperplasia. Patients having surgery to exclude recurrence of PT or that had only a clinical diagnosis of FEL (no CNB) were excluded. When patients had more than one FEL on CNB at presentation the most concerning lesion was included: a lesion that had QPT was included and FA lesions excluded and in cases where the CNB diagnosis was the same, the larger lesion was included. If patients had a second FEL lesion excised during the study period, only the first FEL procedure was included. Demographics, clinical presentation, radiology, pathology, and operative details and follow up/recurrence data were collected.

In our region, patients with breast complaints or abnormal screening mammograms have diagnostic workups, including CNB at 28 diagnostic centers, and are then referred by their primary care physician for surgical management. Fine wire localization was performed where needed and all surgery and surgical pathology were performed at our institution. Review of pathology and radiology at our institution was selective as per our regional process. Original radiology reports were used to determine imaging size and pre-op diagnosis on CNB. The largest reported size from mammography, ultrasound or MRI was used as the imaging size. The type of CNB available at the different diagnostic centers varies with only 5 centers having stereotactic core biopsy. The technique, size of CNB needle and number of passes were at the discretion of the radiologist. CNB results were classified as FA or QPT. PT was classified as Benign, Borderline, or Malignant.

Chi-squared test was used for categorical variables and Student's t-test for continuous variables. Univariable and multivariable logistic regression analyses were conducted to identify risk factors of upstage to PT. To assess the convention of excising FELs at $3 \mathrm{~cm}$ trend analysis was done for FA and QPT cases at various tumor size thresholds. The negative predictive value (NPV) for upstaged tumors were plotted on a spectrum of imaging size thresholds to identify patients who would be more likely to be upstaged to PT based on size. For this analysis the NPV of $95 \%$ was identified. All statistical analysis was performed using R (ver.3.6.1). $\mathrm{P}<0.05$ was considered significant. 


\section{RESULTS:}

Of the 616 patients included in this study, 400 were identified as having FA on CNB and 216 were identified as having QPT. Patients with QPT were older and were more likely to have a palpable and larger lesion (Table 1). All patients with PT had an ultrasound guided CNB. Diagnostic workups were performed at 28 centers with no differences in diagnostic centers between FA and QPT groups ( $\mathrm{p}=0.31)$.

Figure 1 outlines reason for excision and final pathology with 107 cases of PT. No study patients were diagnosed with adenocarcinoma. Seventy-nine cases of PT had QPT on CNB but 28 cases of benign (25) or borderline (3) PT upstaged from FA. The three cases of borderline PT following CNB of FA were 4, 6, $8 \mathrm{~cm}$ in size and had surgery in 2009-10. All patients that upstaged to PT with CNB of FA had a reason for excision of enlarging lesion ( $<<0.001$ ) with a mean size of $38.3 \mathrm{~mm}$.

Follow up information was available for 86/107 patients with PT with a mean of 56 months (Figure 1). Recurrence was found in 6 patients, all of whom had QPT on CNB. For FA patients with imaging sizes of $\geq 30 \mathrm{~mm}$ three had borderline PT all of which had negative margins and the rest had benign PT with 6/22 having positive margins. There was no recurrence at a mean of 48 months follow up. For FA patients with imaging sizes of $<30 \mathrm{~mm}$ all had benign PT at excision and 1 had positive margins. There was no recurrence at a mean of 33 months follow-up.

Logistic regression (Table 2) found a higher risk of PT to be associated with CNB of QPT, older age, and larger lesion. When looking at risk factors for the FA and QPT subgroups larger lesions are more likely to have PT at excision and age is a risk factor in the QPT group (Supplemental Table). We were unable to include indication for excision in this model for FA, as every finding of PT was associated with excision for an enlarging lesion.

To assess the convention of excision FELs at $3 \mathrm{~cm}$ we looked at the chance of finding PT at various sizes (stratified by CNB diagnosis and indication for excision) and performed a trend analysis. Table 3 looks at the risk of finding PT based on CNB diagnosis and last recorded imaging size and stratifies the FA subgroup by whether lesions were enlarging. Fifty-seven (9\%) of patients did not have a recorded lesion size on imaging reports, and instead had narrative descriptions such as "large mass" or "lobulated mass". There were 7 cases of PT in patients with lesions 
less than $30 \mathrm{~mm}$ based on recorded imaging size. On reviewing these cases the physical exam and/or pathology lesion size at excision was $30 \mathrm{~mm}$ or larger in all cases except one in which the imaging and excision specimen demonstrated a $29 \mathrm{~mm}$ lesion. In most cases the imaging size was more than six months prior to surgery with enlargement on physical exam leading to excision. When stratifying patients with FA on CNB by the reason for excision univariate logistic regression showed that lesions with an indication for excision of enlarging lesion had a larger size than lesions with all other indications, except discordance (Table 4).

To further assess the convention of excision at certain sizes and to determine the minimum lesion size required to detect virtually all PT (95\%), the NPV of lesion size cut-off as a diagnostic metric to detect PT was plotted as a function of lesion size (Figure 2). The lesion size required to reach an NPV of $95 \%$, alternatively interpreted as the size below which $95 \%$ of lesions will not be PT, was marked with a vertical dotted line. Among all patients with FA on CNB, lesions smaller than $37 \mathrm{~mm}$ had a $95 \%$ probability of not being PT. The first tumour size threshold among QPT patients where NPV drops below $95 \%$ was at $11 \mathrm{~mm}$, which included the smallest QPT tumour in the study which was upstaged. For the subgroup of FAs indicated for excision for reasons other than enlarging, NPV was $100 \%$ for all sizes because there were no PTs. Put another way, there is no 95\% NPV size cut-off for this group because being excised for any reason other than enlarging mass was associated with not being a PT regardless of lesion size in this cohort. The subgroup of FAs indicated for excision for enlarging lesions had a 95\% NPV threshold at a tumour size threshold of $27 \mathrm{~mm}$ when based on last imaging size (which often was before the enlargement leading to excision, as only one PT was less than $30 \mathrm{~mm}$ at excision).

\section{DISCUSSION:}

Management of CNB-diagnosed FELs remains controversial as current literature reports varying upstage rates to PT. These studies often have a small sample size and their diagnostic imaging and pathology workup limited to a single institution. Our study looks at patients from multiple diagnostic centers demonstrating a high risk of PT (36.6\%) in patients with QPT on CNB and a low risk (7\%) in patients with FA. However, when the FA lesions are stratified by indication for excision all PTs were found in patients having excision for enlarging lesions. In recent years, use of lesion size as a sole discriminatory parameter for FA excision and reliability of the $3 \mathrm{~cm}$ threshold has been questioned $[1,4]$. There seems to be an emerging consensus that the growth rate of FA may be a more useful criteria 
for excision [5, 6-10] and our results further support this. To our knowledge, this is the first study looking at the convention of excision at $3 \mathrm{~cm}$ in a modern cohort and to look at PT recurrence based on CNB diagnosis.

The overall upstage to PT in our study is $17.4 \%$ which is on the lower end of results in the literature for selective excision of FELs that ranges 18-42\% [4, 11-13]. However, when we stratify by the findings on CNB, those patients with FA have a risk of 7\% but those with QPT have a risk of 36.6\%. Logistic regression demonstrates that QPT is a risk factor for PT and the size analysis did not find a size at low risk, supporting our current practice of excising all QPT lesions. These findings are consistent with other studies that have found that in contrast to size, the sensitivity and specificity of pathologists' comment of concern has been reported as $82 \%$ and $93 \%$, respectively [13]. Although further sampling such as larger gauge or vacuum assisted CNB could be considered to try to differentiate PT and FA we believe that excision is appropriate for QPT lesions regardless of size due to the high chance of finding PT.

Patients with CNB of FA have a lower risk of upstage to PT and with FAs thought to occur in 7-13\% [5] of women, defining a low-risk group is an opportunity to spare many women a more invasive surgical procedure. In our patients where the pathologist indicated confidence in the likelihood of FA we found PT at excision in $7 \%$. Because we selectively excise FA this may be an overestimate of the overall rate of detection of PT due to referral and management bias, as non operatively managed patients would not have been included in our study. Although different patients and physicians will have a different perspective on whether surgery is warranted for a $7 \%$ risk of finding PT at excision, our results suggest that risk for FA patients can be further stratified with PT found in $17 \%$ of patients having excision for enlarging lesions and no PT found with other indications for excision; this suggests that enlargement may be a more important consideration than size alone. Other studies have found varying results regarding the significance of size as a criteria for excision; some authors did not find any significant difference in tumor size between groups of FA and PT upon excision $[1,4,11,14]$ while others did find PTs to be larger [8, 15, $16]$.

Clearly, all FAs grow to reach macroscopic size at the time of diagnosis and it is the unknown relationship of growth to timing of CNB that poses the management dilemma. According to Foxcroft et al. [8], FAs usually tend to grow to 20-30 $\mathrm{mm}$ in size and then stabilize or regress on serial ultrasound examination and only a small subset of FAs may 
grow to giant proportions of $60 \mathrm{~mm}$. Gordon et al. [17] calculated FA growth rate and found that FA volume may increase up to $20 \%$ in maximal dimension over 6 months for women of all ages; however, excision is recommended for growth beyond this limit. Similarly, Foxcroft et al. [8] calculated FA growth rate using Gordon's formula and reported that nearly all PTs in their series grew more rapidly than this and recommended that FAs diagnosed on CNB should be followed up at 6 months and again at 12 months to assess rate of growth before excision. Sanders and Sara [9] had two cases of benign PTs in their cohort that were misdiagnosed as FAs on CNB and both of these cases doubled in size (100\% growth) at the first follow-up imaging. Edwards et al. [10] noted that "the only distinguishing clinical feature in patients that upstaged to PT on excision was the clinically apparent rapid growth of biopsy proven FA." We found only one study in which growth rate was not associated with the presence of PT [18]. Our findings further support the importance of enlargement in identifying possible PT.

Similar to other studies, $[8-10,18,19]$ none of the growing FAs in our study upstaged to malignant PT. Hence, the main risk in observing a growing FA is missing a benign/borderline PT as malignant PTs usually have concerning features on CNB. When looking at recurrence of PT following excision and stratifying by preoperative CNB diagnosis all of the recurrences were in patients with QPT on CNB. Importantly, only one patient with PT in our cohort had a lesion $<30 \mathrm{~mm}$ at surgery and we did not see any recurrence of PT in the patients with FA and imaging sizes $<30 \mathrm{~mm}$, supporting that it is reasonable to observe enlarging FAs until they reach about $30 \mathrm{~mm}$ by any examination method.

To assess the convention of excision of FELs at $3 \mathrm{~cm}$ we looked at the chance of finding PT at various sizes stratified by CNB diagnosis and indication for excision and used trend analysis to find the size below which $95 \%$ were not PT (Figure 2). For QPT lesions the $95 \%$ NPV is $11 \mathrm{~mm}$, including the smallest tumor in the cohort which supports excision of all QPT lesions regardless of size. Considering imaging size alone in this group of selectively excised FAs, 95\% of FAs below 37mm were not PT so this analysis does not support routine excision at $3 \mathrm{~cm}$ for FA. Stratifying FA cases into the enlarging lesions and other indications for excision shows low risk even with larger lesions not noted to be enlarging, and further supports observing enlarging FA until they are about $3 \mathrm{~cm}$ in size. This would be consistent with the natural history of FAs which tend to enlarge to 20-30mm [8]. Moreover, 
being able to reassure patients with lesions smaller than these thresholds that surgery will be negative for PT 95\% of the time should help to allay anxiety and decrease surgical intervention.

While our sample size of enlarging FAs is larger than other studies we could not calculate the growth rate due to the lack of standardized follow-up and this is a limitation of the present study. Further study in this area would be beneficial to further refine management algorithms. The other main limitation of this study, in addition to the selection bias of patients having surgery, was lack of consistent imaging size reporting. There were $57(9 \%)$ cases that were missing a quantitative value for imaging size. This is a result of the variability of reporting, and a reflection of real-time clinical practice. Since this study has shown that tumor size can be clinically used as a criterion for excision of FA, it is important to request that diagnostic centers report size information to help determine the course of management. We do note that many of the unknown sizes were in reports from 2009 to 2014 and more recent radiology and pathology reports tend to be more detailed. Another limitation of our data is that we did not perform a central review of pathology or radiology which would increase consistency of diagnostic information. However, we opted to design the study using information that surgeons had, as it came from multiple diagnostic centers, each having multiple radiologists and pathologists. We believe this better reflects the heterogeneity of practice, making results more generalizable than a single institution study.

We see in this study cohort (Figure 1) and our practices that there are a variety of tumor and patient factors that lead to excision. While this study has looked at size and CNB criteria for considering excision some patients will have a smaller lesion that is symptomatic, or discordance on radiology-pathology correlation and these results should not preclude excision in these situations. Conversely, our results support offering follow up to a patient with a lesion at $3 \mathrm{~cm}$ in a larger breast on screening mammography. Having the risks associated with PT and adenocarcinoma from this study will help us to have a more detailed discussion with patients about the surgical and follow up options for their lesions and we anticipate that this will allow for more individualized risk assessment and decision making.

In our cohort of 616 patients from multiple diagnostic centers having selective excision for CNB FEL there were no cases of adenocarcinoma and finding of PT was most strongly correlated with CNB concern for PT (QPT) and indication for excision of FA (enlarging lesion), although age and larger size were also risk factors. For FA patients 
having selective excision $7 \%$ had PT on excision overall; with 17\% having PT when the indication for excision was enlarging lesion and 0\% PT with other indications.

\section{CONCLUSION:}

Traditionally, CNB diagnosed FELs larger than $3 \mathrm{~cm}$ have been surgically excised to avoid missing PT. Our data does not support routine excision of all FELs at $3 \mathrm{~cm}$. Patients with CNB diagnosis of QPT should consider excision regardless of size due to high risk of upstage to PT and association with recurrence. Patients with CNB of FA have a low risk of PT and we recommend that the rate of growth be taken into consideration when deciding on excision of FAs.

\section{ACKNOWLEDGEMENTS:}

The authors would like to acknowledge the input of the physicians in the Departments of Pathology, Surgery, and Radiology in our area that contributed to the development of our clinical pathways. We would also like to acknowledge Dr. Betty Wen who helped with data collection and Mabel Zhang and Crystal Ma who helped with manuscript preparation. 


\section{REFERENCES}

1. Resetkova E, Khazai L, Albarracin CT, et al. Clinical and radiologic data and core needle biopsy findings should dictate management of cellular fibroepithelial tumors of the breast. Breast J. 2010;16(6):573-580. https://doi.org/10.1111/j.1524-4741.2010.01013.x

2. Tan PH, Ellis IO. Myoepithelial and epithelial-myoepithelial, mesenchymal and fibroepithelial breast lesions: updates from the WHO Classification of Tumours of the Breast 2012. J Clin Pathol. 2013;66(6):465-470. https://doi.org/10.1136/jclinpath-2012-201078

3. National Comprehensive Cancer Network. Breast Cancer: NCCN clinical practice guidelines in oncology. https://www.nccn.org/guidelines/guidelines-detail?category=1\&id=1419. Published 2019. Accessed Apr 1, 2020.

4. Wiratkapun C, Piyapan P, Lertsithichai P, et al. Fibroadenoma versus phyllodes tumor: distinguishing factors in patients diagnosed with fibroepithelial lesions after a core needle biopsy. Diagn Interv Radiol. 2014;20(1):27-33. https://doi.org/10.5152/dir.2013.13133

5. Greenberg R, Skornick Y, Kaplan O. Management of breast fibroadenomas. J Gen Intern Med. 1998;13(9):640-645. https://doi.org/10.1046/j.1525-1497.1998.cr188.x

6. Sklair-Levy M, Sella T, Alweiss T, et al. Incidence and management of complex fibroadenomas. AJR Am J Roentgenol. 2008;190(1):214-218. https://doi.org/10.2214/AJR.07.2330

7. Atalay C, Kınaş V, Çelebioğlu S. Analysis of patients with phyllodes tumor of the breast. Ulus Cerrahi Derg. 2014;30(3):129-132. Published 2014 Sep 1. doi:10.5152/UCD.2014.2719

8. Foxcroft LM, Evans EB, Porter AJ. Difficulties in the pre-operative diagnosis of phyllodes tumours of the breast: a study of 84 cases. Breast. 2007;16(1):27-37. https://doi.org/10.1016/j.breast.2006.05.004

9. Sanders LM, Sara R. The growing fibroadenoma. Acta Radiologica Open. April 2015. https://doi.org/10.1177/2047981615572273

10. Edwards T, Jaffer S, Szabo JR, et al. Cellular fibroadenoma on Core needle biopsy: management recommendations for the radiologist. Clin Imaging. 2016;40(4):587-590.

https://doi.org/10.1016/j.clinimag.2016.02.009 
11. Komenaka IK, El-Tamer M, Pile-Spellman E, et al. Core needle biopsy as a diagnostic tool to differentiate phyllodes tumor from fibroadenoma. Arch Surg. 2003;138(9):987-990. https://doi.org/10.1001/archsurg.138.9.987

12. Marcil G, Wong S, Trabulsi N, et al. Fibroepithelial breast lesions diagnosed by core needle biopsy demonstrate a moderate rate of upstaging to phyllodes tumors. Am J Surg. 2017;214(2):318-322. https://doi.org/10.1016/j.amjsurg.2016.12.017

13. Van Osdol AD, Landercasper J, Andersen JJ, et al. Determining whether excision of all fibroepithelial lesions of the breast is needed to exclude phyllodes tumor: upgrade rate of fibroepithelial lesions of the breast to phyllodes tumor. JAMA Surg. 2014;149(10):1081-1085. https://doi.org/10.1001/jamasurg.2014.73

14. Dillon MF, Quinn CM, McDermott EW, et al. Needle core biopsy in the diagnosis of phyllodes neoplasm. Surgery. 2006;140(5):779-784. https://doi.org/10.1016/j.surg.2006.03.022

15. Yohe S, Yeh IT. "Missed" diagnoses of phyllodes tumor on breast biopsy: pathologic clues to its recognition. Int J Surg Pathol. 2008;16(2):137-142. doi:10.1177/1066896907311378

16. Gould DJ, Salmans JA, Lassinger BK, et al. Factors associated with phyllodes tumor of the breast after core needle biopsy identifies fibroepithelial neoplasm. J Surg Res. 2012;178(1):299-303. https://doi.org/10.1016/j.jss.2012.03.059

17. Gordon PB, Gagnon FA, Lanzkowsky L. Solid breast masses diagnosed as fibroadenoma at fine-needle aspiration biopsy: acceptable rates of growth at long-term follow-up. Radiology. 2003;229(1):233-238. https://doi.org/10.1148/radiol.2291010282

18. Dialani V, Chansakul T, Lai KC, et al. Enlarging biopsy-proven fibroadenoma: Is surgical excision necessary? Clinical Imaging. 2019;57:35-39. https://doi.org/10.1016/j.clinimag.2019.03.014

19. Wang Y, Zhu J, Gou J, et al. Phyllodes tumors of the breast in 2 sisters: Case report and review of literature. Medicine (Baltimore). 2017;96(46):e8552. https://doi.org/10.1097/MD.0000000000008552 
Table 1. Patient Characteristics Stratified by Core Needle Biopsy Pathology.

\begin{tabular}{|c|c|c|c|}
\hline Characteristic & $\begin{array}{c}\mathbf{F A}^{\mathbf{a}} \text { on CNB } \\
\mathbf{( 4 0 0}^{\mathbf{b}} \mathbf{\text { patients} )}\end{array}$ & $\begin{array}{c}\mathbf{Q P T}^{\mathbf{c}} \text { on CNB } \\
(\mathbf{2 1 6} \text { patients) }\end{array}$ & P-value \\
\hline Palpable & $258(64.5 \%)$ & $164(75.9 \%)$ & $0.003^{*}$ \\
\hline $\begin{array}{c}\text { Family history of breast } \\
\text { cancer }\end{array}$ & $48(12.0 \%)$ & $41(18.1 \%)$ & 0.051 \\
\hline $\begin{array}{c}\text { Age at OR: } \\
\text { Mean } \pm \text { SD (min-max) }\end{array}$ & $\begin{array}{c}35.5 \pm 11.3(14-78) \\
\mathrm{n}=398\end{array}$ & $\begin{array}{c}39.3 \pm 11.0(16-68) \\
\mathrm{n}=212\end{array}$ & $<0.001^{*}$ \\
\hline $\begin{array}{c}\text { Clinical Exam size (mm)**: } \\
\text { Mean } \pm \text { SD (min-max) }\end{array}$ & $\begin{array}{c}30.0 \pm 13.4(10-80) \\
\mathrm{n}=258\end{array}$ & $\begin{array}{c}34.9 \pm 25.2(10-180) \\
\mathrm{n}=164\end{array}$ & $0.023^{*}$ \\
\hline $\begin{array}{c}\text { Imaging size (mm): } \\
\text { Mean } \pm \text { SD (min-max) }\end{array}$ & $\begin{array}{c}25.8 \pm 12.6(4-82) \\
\mathrm{n}=358\end{array}$ & $\begin{array}{c}30.8 \pm 22.7(7-170) \\
\mathrm{n}=201\end{array}$ & $0.004^{*}$ \\
\hline Type of biopsy & $340(85.0 \%)$ & $168(77.8 \%)$ & $<0.001^{*}$ \\
\hline Ultrasound core biopsy & $42(10.5 \%)$ & $46(21.3 \%)$ & \\
\hline Stereotactic biopsy & $18(4.5 \%)$ & $2(0.9 \%)$ & \\
\hline Fine needle aspirate & 372 & $79(36.6 \%)$ & \\
\hline Phyllodes found at excision & & 136 & \\
\hline Yes & $28(7 \%)$ & $0.001^{*}$ \\
\hline No & & & \\
\hline
\end{tabular}

${ }^{a}$ FA, fibroadenoma

${ }^{\mathrm{b}} \mathrm{CNB}$, core needle biopsy

${ }^{\mathrm{C}} \mathrm{QPT}$, query phyllodes tumor on $\mathrm{CNB}$

$* \mathrm{p}<0.05$

$* *$ for those lesions that were palpable 


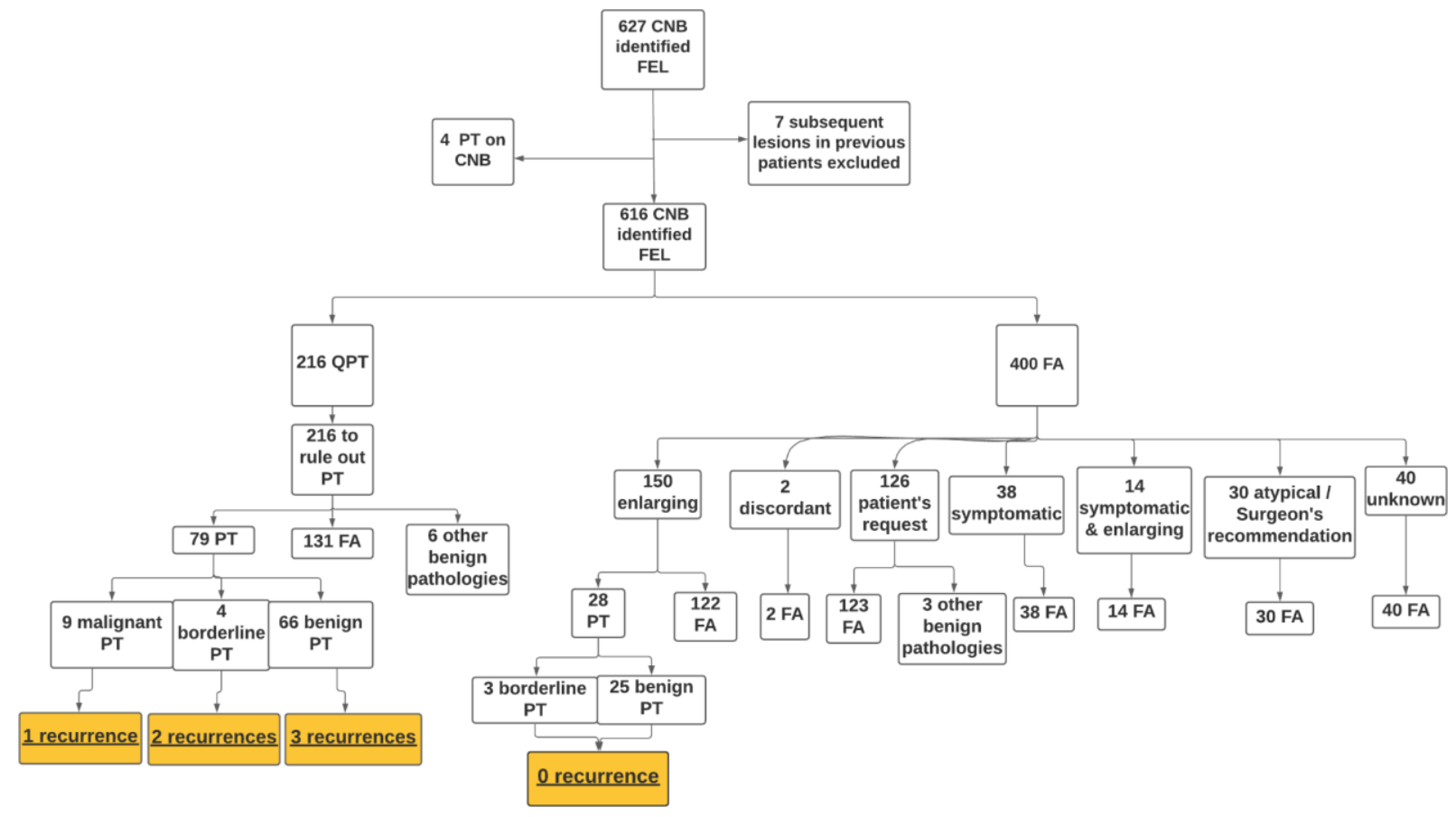

Fig. 1 Breakdown of core needle biopsy (CNB) diagnoses, indication for excision, final pathology and recurrence of PT

FEL, fibroepithelial lesion

FA, fibroadenoma

QPT, query phyllodes tumor

PT, phyllodes tumor 
Table 2. Logistic Regression Analysis CNB Fibroadenoma and Query Phyllodes Tumor

A) Univariate Logistic Regression

\begin{tabular}{|c|c|c|c|c|}
\hline \multirow{2}{*}{ Characteristics } & \multirow{2}{*}{ OR $^{\mathbf{c}}$} & \multicolumn{2}{|c|}{$\mathbf{9 5 \%} \mathbf{C I}^{\mathrm{d}}$} & \multirow{2}{*}{ P-Value } \\
\cline { 3 - 4 } & & Lower & Upper & \\
\hline $\begin{array}{c}\text { Core Needle Biopsy Pathology } \\
\text { (QPT vs FA) }\end{array}$ & 7.661 & 4.826 & 12.478 & $<0.001^{*}$ \\
\hline Age & 1.052 & 1.032 & 1.073 & $<0.001^{*}$ \\
\hline Palpable vs image detected & 2.259 & 1.370 & 3.891 & $0.002^{*}$ \\
\hline Family History of Breast Cancer & 1.639 & 0.935 & 2.782 & 0.074 \\
\hline Max Imaging Size & 1.039 & 1.026 & 1.054 & $<0.001^{*}$ \\
\hline Ultrasound Size & 1.040 & 1.026 & 1.055 & $<0.001^{*}$ \\
\hline Mammography Size & 1.024 & 1.001 & 1.054 & 0.073 \\
\hline
\end{tabular}

B) Multivariate Logistic Regression

\begin{tabular}{|c|c|c|c|c|}
\hline \multirow{2}{*}{ Characteristics } & \multirow{2}{*}{ OR $^{\mathbf{c}}$} & \multicolumn{2}{|c|}{$\mathbf{9 5 \%} \mathbf{C I}^{\mathbf{d}}$} & \multirow{2}{*}{ P-Value } \\
\cline { 3 - 4 } & & Lower & Upper & \\
\hline $\begin{array}{c}\text { Core Needle Biopsy Pathology } \\
\text { (QPT vs FA) }\end{array}$ & 5.018 & 3.016 & 8.531 & $<0.001^{*}$ \\
\hline Age & 1.072 & 1.047 & 1.099 & $<0.001^{*}$ \\
\hline Palpable vs image detected & 1.596 & 0.857 & 3.071 & 0.149 \\
\hline Max Imaging Size & 1.043 & 1.027 & 1.061 & $<0.001^{*}$ \\
\hline
\end{tabular}

${ }^{\mathrm{a}} \mathrm{FA}$, fibroadenoma

${ }^{\mathrm{b}} \mathrm{QPT}$, query phyllodes tumor

${ }^{\mathrm{C}} \mathrm{OR}$, odds ratio

${ }^{\mathrm{d}} \mathrm{CI}$, confidence interval

$* \mathrm{p}<0.05$ 
Table 3. Chance of Finding Phyllodes tumor at excision stratified by last imaging size and Core Needle Biopsy Diagnosis

\begin{tabular}{|c|c|c|c|c|}
\hline \multirow[t]{2}{*}{ Max Imaging Size } & \multicolumn{3}{|c|}{ Fibroadenoma } & \multirow{2}{*}{$\begin{array}{c}\text { Query Phyllodes } \\
\text { Tumor }\end{array}$} \\
\hline & Any & Enlarging & Non-Enlarging & \\
\hline$<10 \mathrm{~mm}$ & $0 / 17(0.0 \%)$ & $0 / 1(0.0 \%)$ & $0 / 16(0.0 \%)$ & $0 / 4(0.0 \%)$ \\
\hline 10 to $<20 \mathrm{~mm}$ & $0 / 109$ (0.0\%) & $0 / 21(0.0 \%)$ & $0 / 88(0.0 \%)$ & $14 / 54(25.9 \%)$ \\
\hline 20 to $<30 \mathrm{~mm}$ & $7 / 111(6.3 \%)$ & $7 / 56(12.5 \%)$ & $0 / 55(0.0 \%)$ & $27 / 75(36.0 \%)$ \\
\hline 30 to $<40 \mathrm{~mm}$ & $12 / 78(15.4 \%)$ & $12 / 51(23.5 \%)$ & $0 / 27(0.0 \%)$ & $11 / 31(35.5 \%)$ \\
\hline $40+$ & $9 / 43(20.9 \%)$ & $9 / 27(33.3 \%)$ & $0 / 16(0.0 \%)$ & $20 / 37$ (54.1\%) \\
\hline
\end{tabular}

** at excision only one patient with PT had a lesion less than $30 \mathrm{~mm}$ but imaging was often done prior to enlargement 
Table 4. Mean imaging size and chance of finding phyllodes tumor at excision by reason for excision

\begin{tabular}{|c|c|c|c|c|}
\hline \multirow{2}{*}{ Histology } & \multirow{2}{*}{$\begin{array}{l}\text { Reason for } \\
\text { Excision }\end{array}$} & \multicolumn{2}{|c|}{ Size $(\mathrm{mm})$} & \multirow{2}{*}{ Finding of PT (\%) } \\
\hline & & Mean $(95 \% \mathrm{Cl}, \mathrm{n})$ & P-Value & \\
\hline \multirow{6}{*}{ Fibroadenoma } & Enlarging mass & $\begin{array}{c}30.5(95 \% \mathrm{Cl}: 28.7 \\
\text { to } 32.4, \mathrm{n}=164)\end{array}$ & Reference & $28(17.4 \%)$ \\
\hline & Patient request & $\begin{array}{c}21.4(95 \% \mathrm{Cl}: 19.5 \\
\text { to } 23.3, \mathrm{n}=126)\end{array}$ & $<0.001^{*}$ & 0 \\
\hline & $\begin{array}{c}\text { Tender or } \\
\text { symptomatic }\end{array}$ & $\begin{array}{c}23.7(95 \% \mathrm{Cl}: 19.3 \\
\text { to } 28.2, n=38)\end{array}$ & $0.003^{*}$ & 0 \\
\hline & $\begin{array}{c}\text { Physician } \\
\text { recommendation, } \\
\text { r/o phyllodes } \\
\end{array}$ & $\begin{array}{c}24.6(95 \% \mathrm{Cl}: 18.6 \\
\text { to } 30.5, \mathrm{n}=30)\end{array}$ & $0.014^{*}$ & 0 \\
\hline & $\begin{array}{l}\text { Discordant btw } \\
\text { CNB and US } \\
\text { appearance }\end{array}$ & $\begin{array}{c}19.5 \text { (95\%Cl: }- \\
113.9 \text { to } 152.9 \\
n=2)\end{array}$ & 0.197 & 0 \\
\hline & Unspecified & $\begin{array}{c}21.7(95 \% \mathrm{Cl}: 18.2 \\
\text { to } 25.1, \mathrm{n}=40)\end{array}$ & $0.001^{*}$ & 0 \\
\hline $\begin{array}{l}\text { Query Phyllodes } \\
\text { Tumor }\end{array}$ & $\begin{array}{c}\text { Concern for } \\
\text { Phyllodes on Core } \\
\text { Needle Biopsy }\end{array}$ & $\begin{array}{c}30.8(95 \% \mathrm{Cl}: 27.8 \\
\text { to } 33.9, \mathrm{n}=216)\end{array}$ & $\mathrm{N} / \mathrm{A}$ & $79(36.6 \%)$ \\
\hline
\end{tabular}

Linear regression analyses were conducted to evaluate the association of mean size with reasons for excision. 
Fig. 2 Negative predictive value (NPV) by tumour size threshold among patients with FA or QPT. The NPV in this figure represents the probability that a mass with Core needle biopsy of Fibroadenoma or Query Phyllodes Tumor smaller than the specified tumour size threshold is a true negative. For each diagnosis, 100 data points are plotted for tumour size thresholds from $1 \mathrm{~mm}$ to $100 \mathrm{~mm}$, and a line is fitted for visualization purposes. A dashed vertical line is used to indicate the smallest threshold where modelled NPV crosses 0.95

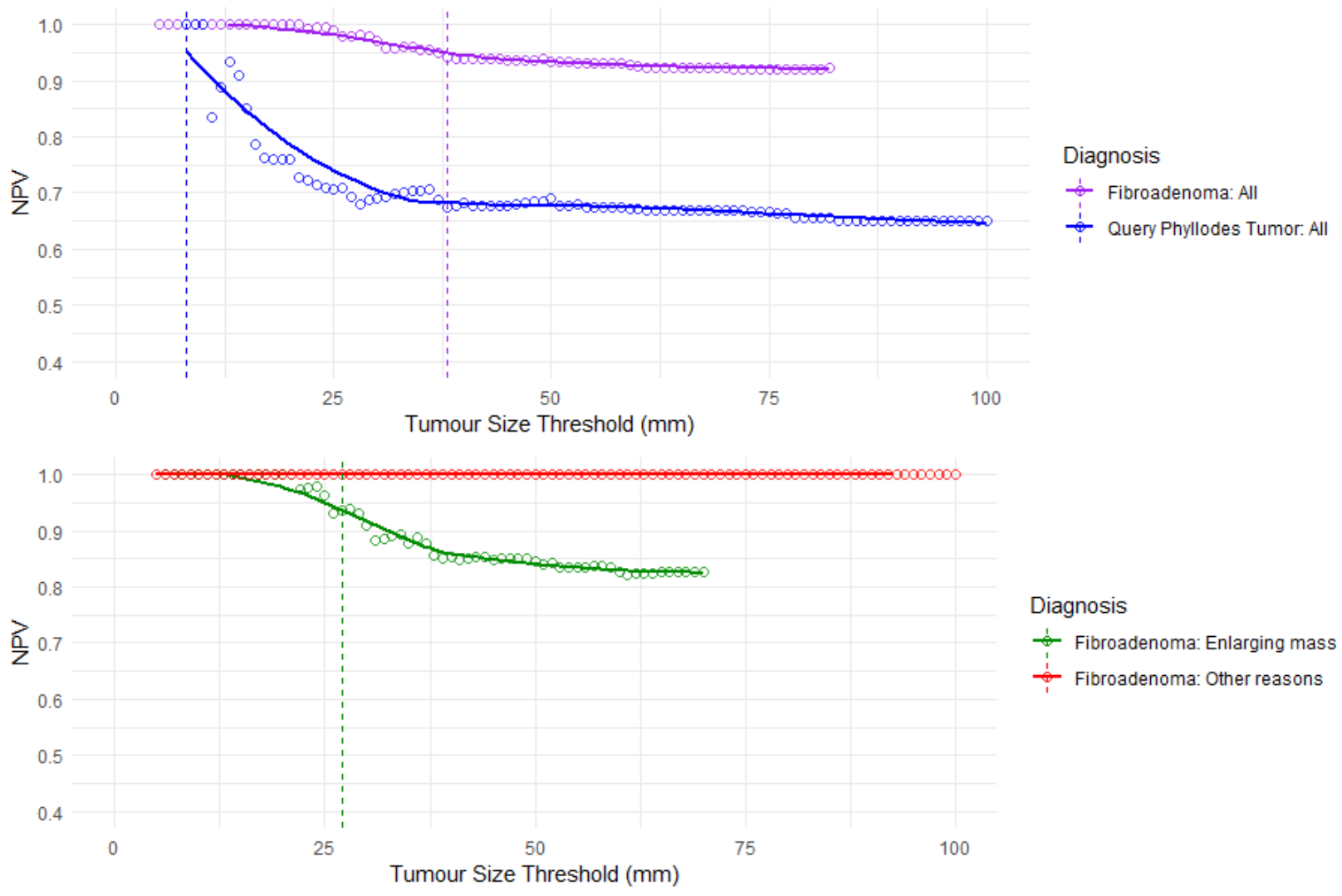


Table for Supplemental Results

Logistic Regression Stratified by Core Needle Biopsy Diagnosis

A) Univariate

\begin{tabular}{|c|c|c|c|c|c|c|c|}
\hline \multirow{2}{*}{$\begin{array}{c}\text { Core Biopsy } \\
\text { Pathology }\end{array}$} & \multirow{2}{*}{ Characteristics } & \multirow{2}{*}{ Comparison } & \multirow{2}{*}{ Reference } & \multirow{2}{*}{ Estimate } & \multicolumn{2}{|c|}{$95 \% \mathrm{CI}^{\mathrm{c}}$} & \multirow{2}{*}{ P-Value } \\
\hline & & & & & Lower & Upper & \\
\hline \multirow{6}{*}{$\mathrm{FA}^{\mathrm{a}}$} & Age & \multicolumn{2}{|c|}{ Continuous } & 14.461 & 4.957 & 61.536 & $<0.001^{*}$ \\
\hline & Palpability & Yes & 1.029 & 0.995 & 1.063 & 0.091 & 0.051 \\
\hline & $\begin{array}{l}\text { Family History of Breast } \\
\text { Cancer }\end{array}$ & Yes & 1.242 & 0.353 & 3.402 & 0.700 & 0.702 \\
\hline & Max Imaging Size & \multicolumn{2}{|c|}{ Continuous } & 1.068 & 1.040 & 1.098 & $<0.001 *$ \\
\hline & Ultrasound Size & \multicolumn{2}{|c|}{ Continuous } & 1.072 & 1.043 & 1.105 & $<0.001^{*}$ \\
\hline & Mammography Size & \multicolumn{2}{|c|}{ Continuous } & 1.041 & 0.987 & 1.100 & 0.124 \\
\hline \multirow{6}{*}{$\mathrm{QPT}^{\mathrm{b}}$} & Age & \multicolumn{2}{|c|}{ Continuous } & 1.057 & 1.028 & 1.088 & $<0.001^{*}$ \\
\hline & Palpability & Yes & 1.579 & 0.815 & 3.180 & 0.186 & 0.138 \\
\hline & $\begin{array}{l}\text { Family History of Breast } \\
\text { Cancer }\end{array}$ & Yes & 1.433 & 0.702 & 2.892 & 0.316 & 0.363 \\
\hline & Max Imaging Size & \multicolumn{2}{|c|}{ Continuous } & 1.024 & 1.010 & 1.041 & $0.003^{*}$ \\
\hline & Ultrasound Size & \multicolumn{2}{|c|}{ Continuous } & 1.024 & 1.010 & 1.042 & $0.003^{*}$ \\
\hline & Mammography Size & \multicolumn{2}{|c|}{ Continuous } & 1.024 & 0.995 & 1.070 & 0.198 \\
\hline
\end{tabular}


B) Multivariate

\begin{tabular}{|c|c|c|c|c|c|c|c|}
\hline \multirow{2}{*}{$\begin{array}{c}\text { Core Biopsy } \\
\text { Pathology }\end{array}$} & \multirow{2}{*}{ Characteristics } & \multirow{2}{*}{ Comparison } & \multirow{2}{*}{ Reference } & \multirow{2}{*}{ Estimate } & \multicolumn{2}{|c|}{$95 \% \mathrm{CI}^{\mathrm{c}}$} & \multirow{2}{*}{ P-Value } \\
\hline & & & & & Lower & Upper & \\
\hline \multirow{3}{*}{$\mathrm{FA}^{\mathrm{a}}$} & Age & \multicolumn{2}{|c|}{ Continuous } & 1.055 & 1.018 & 1.095 & $0.003^{*}$ \\
\hline & Palpability & Yes & 1.802 & 0.624 & 6.187 & 0.305 & 0.367 \\
\hline & Max Imaging Size & \multicolumn{2}{|c|}{ Continuous } & 1.073 & 1.044 & 1.105 & $<0.001 *$ \\
\hline \multirow{3}{*}{$\mathrm{QPT}^{\mathrm{b}}$} & Age & \multicolumn{2}{|c|}{ Continuous } & 1.090 & 1.054 & 1.131 & $<0.001 *$ \\
\hline & Palpability & Yes & 1.543 & 0.705 & 3.491 & 0.285 & 0.357 \\
\hline & Max Imaging Size & \multicolumn{2}{|c|}{ Continuous } & 1.030 & 1.013 & 1.050 & $0.001 *$ \\
\hline
\end{tabular}

${ }^{\mathrm{a}} \mathrm{FA}$, fibroadenoma

${ }^{\mathrm{b}} \mathrm{QPT}$, query phyllodes tumor

${ }^{\mathrm{c}} \mathrm{CI}$, confidence interval

$* \mathrm{p}<0.05$ 